\title{
HYGROTHERMAL EFFECT ON MECHANICAL PROPERTIES OF VINYLESTER/CARBON AND ISOPOLYESTER/CARBON COMPOSITES
}

Kanchiraya $\mathrm{S}^{1}$, Shivakumar $\mathrm{S}^{2}$

\begin{abstract}
The aim of the research work was to investigate the effect of hygrothermal on mechanical properties such as tensile, flexural and interlaminar shear strength of vinylester/carbon and Isopolyester /carbon composites exposed at a temperature of $60^{\circ} \mathrm{C}$ for 196 days in artificial sea water. Both composites exhibited reduction of mechanical properties due to higher moisture absorption at initial stages, but in the longer duration saturation in mechanical properties was observed. The UTS and flexural strength of vinylester/carbon dropped by about $3.20 \%$ and $5.07 \%$ respectively, while for isopolyester/carbon composites the reduction was $9.42 \%$ and $11.03 \%$ respectively. The moisture observation of vinylester/carbon composites was superior compared to isopolyester/carbon composites. SEM images of fracture surface of carbon reinforced composite samples were analysed.
\end{abstract}

Keywords: CFRC's, Degradation studies, tensile, flexural, ILSS, Artificial seawater, SEM

\section{INTRODUCTION}

Carbon fibre reinforced composites (CFRC's) find numerous applications such as in aerospace, marine and terrestrial structures due to their high specific stiffness and durability[1-2]. CFRC's have the capacity to retain their mechanical properties at different conditions such as temperature variations, moisture, sunlight, oxidation, microbiological attack and even marine environmental conditions [3-5]. Several researchers have investigated the properties of CFRC's at room temperature in marine environment conditions. They revealed that the inference of carbon fiber/epoxy polymers degraded by hydrolysis at saline environment due to reaction of unsaturated polymer group [6]. The effect of degradation may cause swelling, plasticization, debonding and even degradation in mechanical properties. The moisture absorption damages the interfacial bonding between the fiber and matrix which leads impairment of mechanical properties [7]. The residual stresses induced due to water absorption leads to breaking of adhesion bond and formation of microcrack in the composites [8]. To overcome these effect researchers recommended vinylester based polymer composites due its higher chemical inertness in the saltwater [9-10]. Vinylester based composites retain their physical and mechanical properties when immersed in saltwater at longer duration. One of the main drawbacks of

\footnotetext{
${ }^{1}$ Dept. of Mechanical Engineering, Govt. Engg. College, Hassan, 573201, India

${ }^{2}$ Dept. of I\&PE, GIT, Belgavi, 590008, India
} 
thermoset polymers in seawater is that the polymer matrix and fibre/matrix interface can be degraded by the hydrolysis reaction of unsaturated groups within the resin [11]. Seawater degradation can cause swelling and plasticization of the polymer matrix and debonding at the fibre/matrix interface that may reduce the mechanical properties. This problem can be alleviated by using vinylester based composites that generally have superior chemical stability in seawater [12-13]. When used in marine applications, the vinylester/carbon composites retain their mechanical properties and show minimum degradation when immersed in seawater even after many years [14]. The modulus of vinylester/glass composites possesses values lower than 40 $\mathrm{GPa}$ due to the lower modulus of glass fibres $(70 \mathrm{GPa})$ and it is difficult to build marine structures like unmanned underwater vehicles using these composites. Glass counterpart carbon fibre has high modulus (250 GPa), which can replace glass in marine applications especially for unmanned underwater applications [15]. Eventhough many researchers worked on hygrothermic behavior of polymer composites, but few research work was focused on comprehensive study and comparative results on the hygrothermal effect on the composite system especially carbon based polymer composites. Thus the objective of the work was to investigate on hygrothermal degradation for vinylester/carbon and isopolyester /carbon composites in sea water immersion at a temperature of $60^{\circ} \mathrm{C}$.

\section{EXPERIMENTAL STUDY}

The vinylester/carbon fibre and isopolyester/carbon fibre composites specimen were fabricated using hand layup process. Before lay-up, the Teflon mould was applied with a mould releasing agent (Paraffin wax) to ensure smooth removal of the laminate from the mould and to avoid its adhesion to the mould. The fibre: matrix ratio of $\quad 65: 35 \mathrm{wt} \%$ was maintained for all the specimens. A brush was used to impregnate the fibres with the resin. The resin was applied uniformly throughout the fibre plies and stacking them in the Teflon mould. The specimens were cured at room temperature for two weeks as most of the materials for marine applications are naturally cured, before exposing to experimental conditions. The edges of the panels were sealed using the matrix resin before exposing to the experimental medium. This was to prevent the moisture permeation through these sides. Further the composite specimens were naturally cured for 10 days at room temperature before hygrothermal exposure.

The composite panels were immersed in a large tank containing artificial seawater prepared according to ASTM D 1141 (chemical compositions are $\mathrm{NaCl}-28.2 \%, \mathrm{CaCl}_{2}-1.54 \%$ and $\mathrm{MgCl}_{2}-11.2 \%$ ) with salinity content of about $2.9 \%$ and room temperature for different time periods. The artificially prepared seawater in the tank was renewed periodically. Specimens were periodically withdrawn from the tank and weighed for water uptake. The dimensions of the specimen for different tests are given in the Table 1.

Table 1. The dimension of the carbon based composites as per ASTM standard [10]

\begin{tabular}{|l|l|l|}
\hline Test type & Dimension in $\mathrm{mm}$ & ASTM Standard \\
\hline Flexural test & $127 \times 12.5 \times 3$ & ASTM D 790 \\
\hline $\begin{array}{l}\text { Interlaminar } \\
\text { shear strength }\end{array}$ & $24 \times 6.35 \times 3$ & ASTM D2344 \\
\hline Tensile test & $216 \times 19 \times 3$ & ASTM D 638 \\
\hline
\end{tabular}


The specimen were removed at prescribed interval for determine their properties, and further dried to measure the increase in weight by an electronic balance which can weight upto $0.001 \mathrm{mg}$. The difference in initial and final weight were calculated for the increase in weight of the specimen using electronic balance to measure the moisture diffusion. Ultimate tensile strength, Flexural strength and inter laminar shear strength of the specimen aged in different duration were determined. The mechanical tests were conducted using a Universal Testing Machine(UTM). Three specimens were used and the average values were presented for analysis. The flexural strengths of the specimens were determined for different exposure conditions using the threepoint bending test as per

ASTM-D790 using UTM.

\section{RESULTS AND DISCUSSIONS}

\subsection{Durability studies at hygrothermic condition.}

The Ultimate tensile strength (UTS) of specimen exposed in hygrothermic condition were carried out at room temperature. The experimental results were analysed and performance prediction were done based on the UTS results over duration of 196 days at $60^{\circ} \mathrm{C}$ temperature and $95 \%$ relative humidity. For UTS of vinylester/carbon specimens, the degradation was $3.2 \%$ at $60^{\circ} \mathrm{C}$. For isopolyester/carbon samples the degradation was $11.03 \%$ as shown in Fig. 1. The reduction in flexural strength of vinylester/carbon is 5.07\% and for isopolyester/carbon is $9.42 \%$ for 196 days at $60^{\circ} \mathrm{C}$ hygrothermic condition. The flexural strength decreases due to absorption of seawater by the composites and leading the material to moisture induced degradation in the fibre/matrix interface. The flexural strength reduced as shown in Fig 2. Vinylester/carbon specimens showed $8.57 \%$ degradation where as isopolyester/carbon specimen showed reduction in ILSS of $10.5 \%$ at $60^{\circ} \mathrm{C}$ for duration of 196 days at hygrothermic conditions. The ILSS is one of the important properties for composites that determines the load sharing by the fibres, that is the interfacial strength. The trend in the ILSS degradation behaviour is shown in Fig. 3. Vinylester/carbon specimens showed $8.57 \%$ degradation whereas isopolyester/carbon specimen showed reduction in ILSS of $10.5 \%$ at $60^{\circ} \mathrm{C}$ for duration of 196 days at hygrothermic conditions. The similar observations at higher duration and temperature had higher moisture absorption as reported by Chen et.al [16-17].

All the composite specimen analysed showed degradation in UTS, flexural strength and ILSS due to hygrothermic condition. Degradation increased with increase in time and temperature $\left(60^{\circ}\right.$ C) and of water that penetrates into the interface through the microvoids and microcracks and the trapped water damages the interface region. Vinylester/carbon showed reduced degradation than isopolyester/carbon.

\subsection{Strength degradation due to artificial seawater immersion.}

Tensile strength of composites after immersion into artificial seawater for different time periods was analyzed. It clearly indicates that degradation increases substantially with increase of immersion time as shown in Fig. 4. The degradation of composite property is a function of absorbed moisture. The rate of moisture absorption (diffusion) is a function of temperature. The degradation of vinylester/carbon $(5.45 \%)$ is less as compared to isopolyester/carbon (12.52\%).Fig 5 exhibits change in flexural strength of vinylester/carbon and isopolyester/carbon composites with respect to different immersion time (days). All the specimens shows drop in 
flexural strength of isopolyester/carbon composites with increase in immersion time because of moisture absorption. Vinylester/carbon composite specimens exhibited small reduction in degradation of $5.41 \%$ while for isopolyester/carbon specimens, the degradation was $5.57 \%$. The trend in ILSS degradation behaviour was observed and shown in Fig. 6. ILSS is one of the important properties for composites, which determines the load sharing by the fibres. Vinylester/carbon samples showed superior stability in ILSS degradation with $8.3 \%$ of drop and isopolyester/carbon showed a drop of $10.76 \%$. Artificial seawater in the resins causes vibration and rotation on the cross link that may break the bonds. Surface changes in the isopolyester/carbon on artificial seawater immersion reduces the strength of the fibre and the reason for degradation in the ILSS is the material reinforced [18].

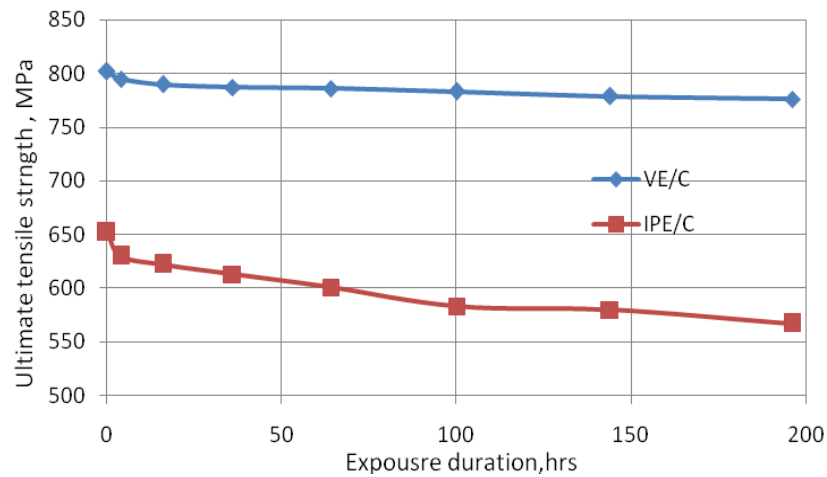

Fig. 1. Ultimate tensile strength versus duration due to hygrothermic condition at $60^{\circ} \mathrm{C}, 95 \% \mathrm{RH}$

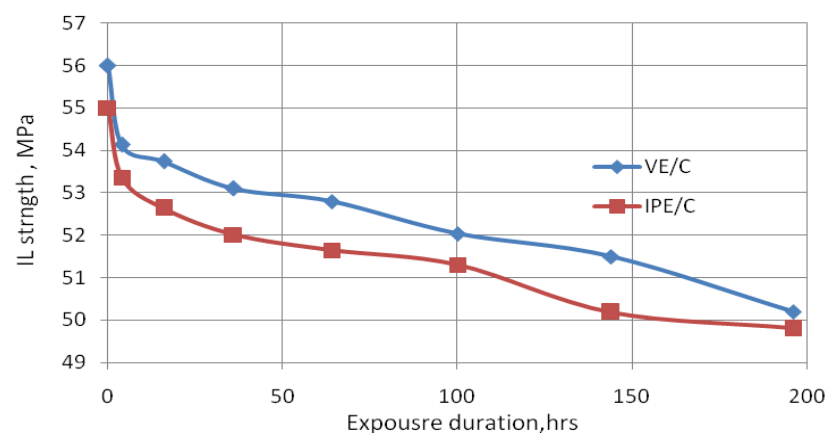

Fig. 3.Interlaminar shear strength versus duration due to hygrothermic condition at $60^{\circ} \mathrm{C}, 95 \% \mathrm{RH}$

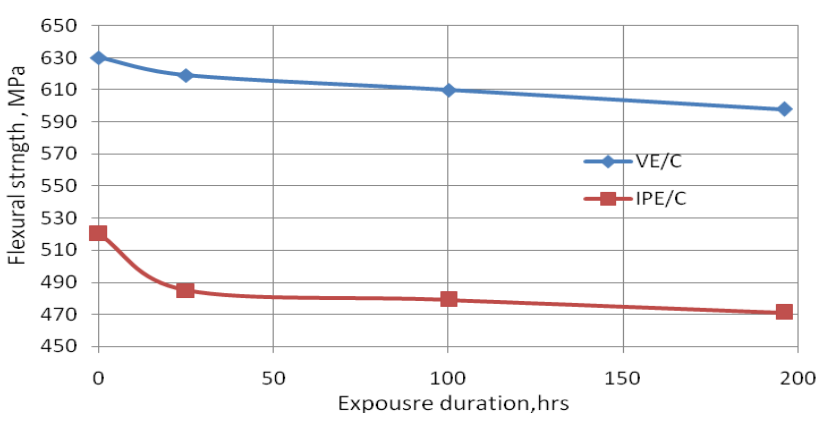

Fig. 2. Flexure strength versus duration due to hygrothermic condition at $60^{\circ} \mathrm{C}, 95 \% \mathrm{RH}$

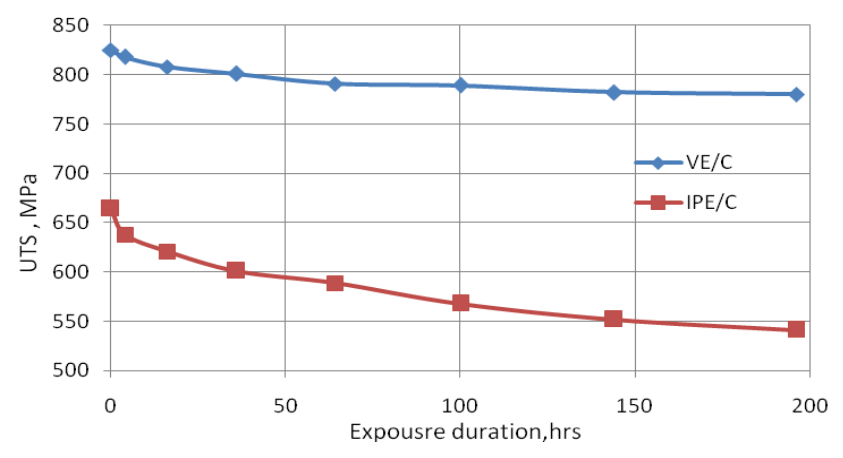

Fig. 4. Ultimate tensile strength degradation verses duration of saltwater immersion at condition of $60^{\circ} \mathrm{C}$ 


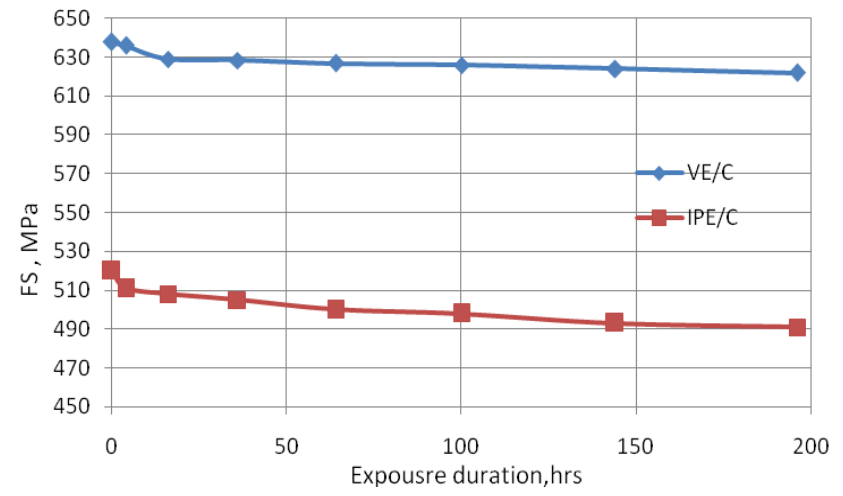

Fig. 5. Flexural strength degradation verses duration of saltwater immersion condition of $60^{\circ} \mathrm{C}$.

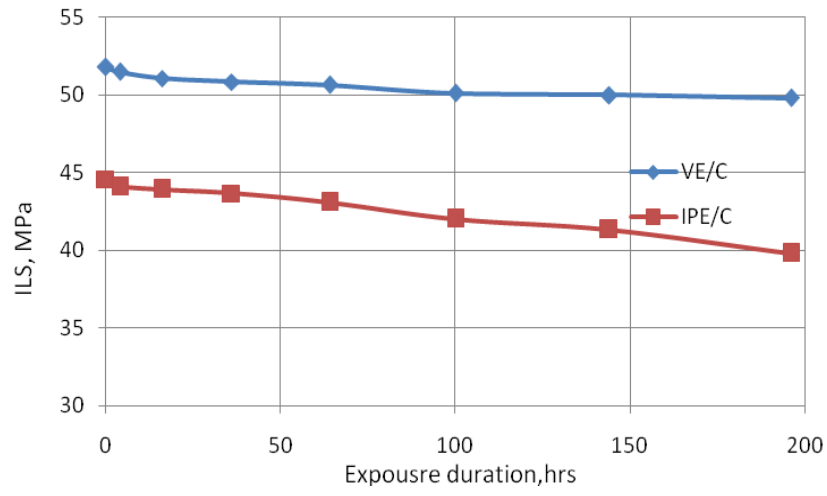

Fig. 6. Inter laminar shear strength degradation verses duration of saltwater immersion condition of $60^{\circ} \mathrm{C}$.

The difference in the extent of degradation in the specimens is due to the much greater resistance of the vinyl ester resin to hydrolytic degradation than that of the isopolyester resin [19]. The quantity of leached organic species is very lower in vinyl ester based composites because of the superior chemical stability of these composites in seawater [20]. Water can cause chemical degradation of isopolyester resulting in lower fracture energies in the presence of moisture [21]. Hence vinyl ester based composites show greater degradation compared to isopolyester based composites.

\subsection{Fracture surface studies.}

SEM provides evidence of the bonding between the resin/fibre before and after the seawater immersion. The degradation in mechanical properties is due to the degradation in the resin/fibre interfacial bonding. The voids present in the matrix are the main reason for moisture diffusion.
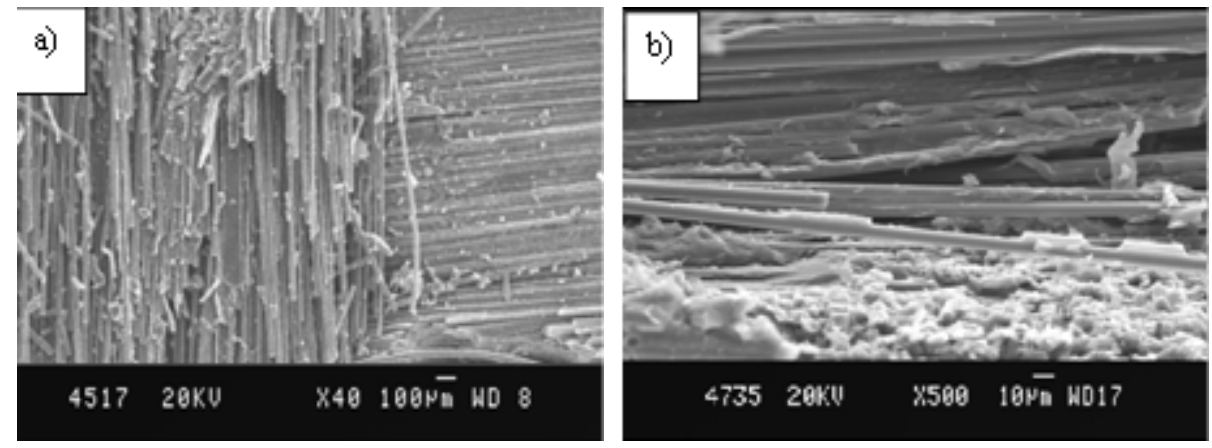

Fig. 7 SEM images of fracture surface of carbon reinforced composite samples after immersion in seawater (a) Vinylester / carbon and (b) isopolyester/carbon composites

After 196 days of exposure, the composite specimen isopolyester/carbon exhibited increased degree of debonding, matrix degradation and plasticization compare to vinylester/carbon. The matrix failure and fibre pull out was observed dominantly in isopolyester/carbon specimens. 
Vinylester/carbon showed lowest amount of fibre pull out due to greater chemical resistance of vinylester to seawater Fig. 7(a). It is evident from the SEM images that the reduction in bond strength has a strong correlation with the reduction in tensile strength. Figure 7(b) shows a higher level of surface degradation and pitting, and also numerous bare debonded fibres, which substantiates the fact that the reduction in transverse strength is largely due to fibre/matrix interfacial degradation. Images of the fracture section fig 7 indicate relatively good bonding between the fibre and the matrix at the interface. Only vinylester/carbon specimens in both conditions corresponding to SEM presented in Figure 7(b) clearly shows degradation of the matrix i.e. epoxies due to moisture absorption even at lower magnification. The matrix degradation is not too pronounced in case of vinylester this evidences the drop in mechanical properties to lower extent in vinyl ester specimens. Thus, Vinylester is the better candidate for underwater structural applications.

\section{CONCLUSION}

In this study, the effect of fibrous reinforcement and solvent content on water absorption composite after immersion in artificial seawater and hygrothermal ageing was investigated experimentally. Two types of resin solvent and one type of reinforcement were used. The isopolyester/carbon is less stable in seawater than vinylester/carbon composites. The isopolyester/carbon composites exhibits degradation at the fibre matrix interface, but no significant change in tensile strength and modulus properties were observed in vinylester/carbon composites after exposure to seawater at room temperature and $60^{\circ} \mathrm{C}$.

\section{REFERENCES}

[1] Deanna N.Busick and Mahlon S. Wilson. "Low-cost composite materials for PEFC bipolar plates, Fuel cells Bulletion" vol.2, No.5, 6-8. 2006.

[2] G.Sala. "Composite degradation due to fluids absorption”, composites parts B: Engineering, vol.31, Issue 5, July 2000, 357-373.

[3] H.Gu. "Behaviors of glass fibre/unsaturated polymer composite under seawater environment" materials and design, vol.30.n o.4, 1337-1340, 2009.

[4] Bergeret L.Ferry, and P.Ienny. "Influence of fiber/matrix interface on ageing mechanisums of glass fibre reinforced thermoplastic composites (PA-6, pet, PBT) in a hygrothermal environment", polymer degradation and stability, vol.94, no.9, 2009, 1315-1324.

[5] A.Kouadri-Boudjelthia, A. Imad,A. Bouabdallah, and M.Elmeguenni, "Analysis of the effect temperature on the creep parameters of composite materials", materials and design, vol.30,no.5, 2009, 1569-1574.

[6] R.M. Guedes, "Durability of polymer matrix composites: Viscoelastic effect on static and fatigue loading", Composites science and Technology, vol. 67, no.11-12, 2007,2574-2583.

[7] P. Purneel, J, Cain, P.Van Itterbeeck, and J.Lesko", Sevvice life modeling of fibre composites: a unifield approach", Composite and Technology, vol.68, no.15-16, 2008, 3330-3336.

[8] Miyano, Y. Nakada. M, Kudo. H and Muki R,Predection of Tensile Fatique life under Temperature environment for unidirectional CFRP, Advanced composite materials, vol. 8,235-246, 1999.

[9] Miyano, Y. Nakada M, and Sekine, N., "Accelerated testing for Long-term durability of FRP laminates for marine use", Journal of composite materials, no.39, 5-20, 2005.

[10] ASTM committee: standard test method for tensile properties of polymatrix composite material, Annu. Book ASTM stand. D3039-00, 2000.

[11] J.R.M. d'Almeida, R.C. de Almeida and W.R. de Lima, "Effect of water absorption of the mechanical behavior of fiberglass pipes used for offshore service water", Composite Structures, Vol. 83, (2008), pp. 221225.

[12] Nikhil Joshi, Anastasia Muliana, "Deformation in viscoelastic sandwich composites subject to moisture diffusion”, Composite Structures, Vol. 92 (2010), pp. 254-264. 
[13] Botelho EC, Costa ML, Pardini LC, Rezende MC, "Processing and hygrothermal effects on viscoelastic behavior of glass fiber/epoxy composites". Journal Material Science Vol.40 Issue14,(2005), pp.3615-23.

[14] Kumosa, B. Benedikt, D. Armentrout, M. Kumosa, "Moisture absorption properties of unidirectional glass/polymer composites used in composite (non-ceramic) insulators" Composites Part A, Vol.35 (2004), pp. 1049-1063.

[15] A.P.Mouritz, E.Gellert, P.Burchill, K, Challis, "Review of Advanced Composite Structures for Navel Ships and Submarines", Composites Structures, Vol.53 (2001), pp. 21-41.

[16] Chen, R. S., Sahrim, A and Gan, S. Characterization of Rice Husk-Incorporated recycled thermoplastic blend composites. BioResources 11(4), 8470-8482.”

[17] Chen, R. S., Mohd Hafizuddin, A. G., Mohd Nazry, S., Sahrim, A and Tarawneh, M. Mechanical, water absorption, and morphology of recycled polymer blend rice husk flour biocomposites. Journal of Applied Polymer Science 132(8), 2461-2472.

[18] A.M. Visco, L.Calabrese and P. Cianciafara, "Modification of polyester resin based composite induced by seawater absorption", Composite- Part A, Vol.39, (2008), pp. 805-814.

[19] Apicell A, Migliaresi C, Nicolais L, Roccotelli S, "The water ageing of unsaturated polyester-based composites: influence of resin chemical Structure, Composites (1983) vol. 14; pp.387-392.

[20] A Kootsookos \& A P Mouritz, "Seawater durability of glass- and carbon-polymer composites", Composites Science and Technology, vol. 64, (2004) pp.1503-1511.

[21] Michalke, T A and B C Bunker, 1987, "The Fracturing of Glass," Scientific American (December) 122-129. 